\title{
No Evidence for Temperature-Dependence of the COVID-19 Epidemic
}

\author{
Tahira Jamil ${ }^{1,2 *}$, Intikhab Alam ${ }^{1}$, Takashi Gojobori ${ }^{1}$ and Carlos M. Duarte ${ }^{1,2 *}$ \\ ${ }^{1}$ Computational Bioscience Research Center (CBRC), King Abdullah University of Science and Technology, Thuwal, Saudi \\ Arabia, ${ }^{2}$ Red Sea Research Centre (RSRC), King Abdullah University of Science and Technology, Thuwal, Saudi Arabia
}

The pandemic of the COVID-19 extended from China across the north-temperate zone, and more recently to the tropics and southern hemisphere. The hypothesis that COVID-19 spread is temperature-dependent was tested based on data derived from nations across the world and provinces in China. No evidence of a pattern between spread rates and ambient temperature was found, suggesting that the SARS-CoV-2 is unlikely to behave as a seasonal respiratory virus.

Keywords: COVID-19, epidemic, temperature, exponential rate, $\mathbf{R t}$

\section{OPEN ACCESS}

Edited by:

Craig Stephen,

University of Saskatchewan, Canada

Reviewed by: Maquins Odhiambo Sewe,

Umeå University, Sweden Maya K. Gislason, Simon Fraser University, Canada

*Correspondence:

Tahira Jami

tahira.jamil@kaust.edu.sa

Carlos M. Duarte

carlos.duarte@kaust.edu.sa

Specialty section:

This article was submitted to

Planetary Health,

a section of the journal

Frontiers in Public Health

Received: 27 March 2020

Accepted: 16 July 2020

Published: 26 August 2020

Citation:

Jamil T, Alam I, Gojobori T and Duarte CM (2020) No Evidence for

Temperature-Dependence of the COVID-19 Epidemic.

Front. Public Health 8:436.

doi: 10.3389/fpubh.2020.00436

\section{INTRODUCTION}

On 30th January the WHO declared the novel coronavirus (COVID-19) outbreak a public health emergency of international concern (http://www.euro.who.int/en/home). The epidemic spread gradually from Wuhan province in China, to other Asian nations, the middle east and Europe. By early March the epidemic was mostly concentrated in territories extending between 30 and $50^{\circ}$ $\mathrm{N}$ (1), now in late winter, leading to the suggestion, echoed by the global media, that the epidemic is likely to be temperature-dependent. This supported speculation of possible decline in severity with the onset of warmer spring and summer temperatures in north-temperate latitudes $(1,2)$, comparable to many viruses affecting human respiratory systems, including SARS $(3,4)$.

However, recent (updated up to May 31, 2020; cf. Methods) data revealed the spread of the epidemic across territories experiencing warm temperatures in the tropics (e.g., Indonesia, Singapore, Brazil) and southern hemisphere as well (e.g., Australia, Argentina). The current distribution of the epidemic challenges, therefore, the inference that SARS-CoV-2 may behave as a seasonal respiratory virus based on previous statistical analyses from earlier realized distributions.

Here we examine the relationship between the apparent exponential rate of SARS-CoV-2 spread $(\gamma)$ and the Effective Reproductive number (Rt) of infection and the average daily temperature $\left(\mathrm{T}_{\text {avg }}\right)$ across nations and Chinese provinces where epidemics, with at least 1,000 cases reported, have been reported (data updated up to 31 May, 2020).

\section{METHODS}

\section{Novel Coronavirus (COVID-19) Cases Data}

The Novel Coronavirus (COVID-19) daily data are confirmed cases for affected countries and provinces of China reported between 31st December 2019 and 31st May 2020. The data was collected from the reports released by WHO, European Centre for Disease Prevention and Control (ECDC), and John Hopkin CSSA. Data include confirmed and a cumulative total of COVID-19 cases in affected countries/provinces. 


\section{Average Ambient Temperature}

The average temperatures of all the affected countries were collected from https:/www.timeanddate.com/weather/. The monthly mean temperature of February to May 2020 of capital cities for the various nations were used as reference temperatures for the country.

\section{Statistical Analysis}

To avoid the estimates to be biased by confinement measurements rather than displaying the epidemic spread, we calculated the exponential rate and Effective reproduction number (Rt) of epidemic spread for the period of exponential growth in number of cases, which was defined as that showing a linear slope when plotting number of cases vs. time. We analyzed the data where the COVID-19 incident has at least a 10-day growth period, and the total number of cases was at least 1,000.

Hence, we fitted the exponential model to each country and each province of China and calculated exponential rate parameters for the countries

$$
\begin{aligned}
N & =a e^{\gamma \text { Days }}, \quad \gamma>0 \\
\log N & =\alpha+\gamma \text { Days. }
\end{aligned}
$$

Where $\mathrm{N}$ is the cumulative number of diagnosed persons and Days is the number of days and $\gamma$ is the exponential rate (100 $\mathrm{x} \gamma=\%$ increase per day).

To calculate the effect of temperature on the exponential rate parameter, we first regressed the exponential rate parameters retrieved from the exponential model on $T_{\text {avg }}$ and $T_{a v g}^{2}$

$$
\gamma \sim T_{a v g}+T_{a v g}^{2}
$$

If the squared term is significant, it provides evidence of non-linearity.

The thermal performance of COVID-19 was characterized by fitting spread rate estimate or growth parameter $(\gamma)$ and temperature to the Gaussian function;

$$
\gamma=a e^{\left[-0.5\left(\frac{\left(T_{\text {avg }}-o p t\right)}{\text { tol }}\right)^{2}\right]},
$$

$T_{\text {avg }}$ is the average temperature (in ${ }^{\circ} \mathrm{C}$ ) that best encompasses the growth period of COVID-19 cases since its 100 incidences in a country/region of China. Where, amplitude $(a)$ is the coefficient related to maximum of spread rate of countries, the optimum $(o p t)$ on the temperature gradient is where the maximum of spread rate is attained and the tolerance (tol) gives the width of the response curve. This model has non-linear form, and the model parameters opt and tol occur non-linearly in the model function. Parameter of thermal performance curve was estimated by fitting Gaussian model to the growth rate and temperature of infected countries. The initial values for the Gaussian parameters $o p t, t o l$, and $a$ were obtained directly using maximum-likelihood polynomial regression for the Gaussian function.

Estimated the Effective reproductive number (Rt), the average number of infections at time $t$, per infected case over the course of their infection for COVID-19 for provinces of China and other countries using a discrete $\gamma$ distribution with a mean of 4.8 days and a standard deviation of 3.5 days for the serial interval distribution.

All analyses were performed using $\mathrm{R}$ statistical computing software. The data set is available from Jamil et al. (5).

\section{RESULTS}

Our results show that evidence for a temperature-dependence of the transmission reported in previous papers was likely to be spurious, reflecting the pathways of spread, and that there is no evidence for thermal dependence of the transmission across the $1-34^{\circ} \mathrm{C} \mathrm{T}_{\text {avg }}$ range across the affected regions. This suggests little basis to expect evidence for the virus to behave as a seasonal respiratory virus.

Epidemiological data consisting in the rate of increase in accumulated diagnosed cases among nations (global) shows $\gamma$ ranging from $3.4 \% \mathrm{day}^{-1}$ to $25.8 \% \mathrm{day}^{-1}$ (Figure S1), with an average of $12.06 \pm 0.45 \% \mathrm{day}^{-1}$ (Figure 1, Figure S1), and apparent Rt of $1.4 \pm 0.02$ (Figure 1). Surprisingly, $\gamma$ and Rt across Chinese provinces (mean $\pm \mathrm{SE}=10.17 \pm$ $0.96 \% \mathrm{day}^{-1}$ and $1.17 \pm 0.04$ ) were below those of other nations (mean $\pm \mathrm{SE}=12.06 \pm 0.45 \% \mathrm{day}^{-1}$ and 1.4 \pm 0.02 ), possibly because much faster confinement of the Chinese population did not allow for the potential exponential rates under uncontrolled conditions to be realized. The broad variability in realized $\gamma$ and Rt between nations (global) and provinces (China) largely reflects differences in detection likelihood along with the timing and rigor of adoption of confinement measures.

The relationship between $\gamma$ and $\mathrm{Rt}$ and $\mathrm{T}_{\text {avg }}$ shows no evidence for a reduced spread rate with warming (Figure 1), unlike analyses based on previous data. A number of nations with $\mathrm{T}_{\mathrm{avg}}>20^{\circ} \mathrm{C}$, including subtropical and tropical (Brazil, Qatar, Saudi Arabia, UAE, India, and Indonesia), and southern-hemisphere (Peru, Chile, Argentina) nations (Figure 2), support $\gamma$ and Rt above the median values of $11.3 \% \mathrm{day}^{-1}$ and 1.38 , respectively (Figure 1). However, the same analysis conducted on earlier data of 15th March, did provide some evidence for low $\gamma$ and Rt for $\mathrm{T}_{\text {avg }}>20^{\circ} \mathrm{C}$ (Figure S2). Our updated results (Figure 1) and same analysis conducted on 27th March and 31st May (Figures S3, S4) show, however, that this apparent temperature-dependence was confounded with a prevailing zonal pattern of spread across the north-temperate zone, possibly reflecting the main patterns of human mobility, which delayed arrival of the epidemics to the southern hemisphere and the tropics.

\section{DISCUSSION}

The results suggest that, contrary to prior assessments, the spread rate of the COVID-19 pandemic is temperature-independent, suggesting that there is little hope for relief as temperatures in the northern hemisphere increase, and that poor nations with weak health systems in tropical regions, such as African, are at great 

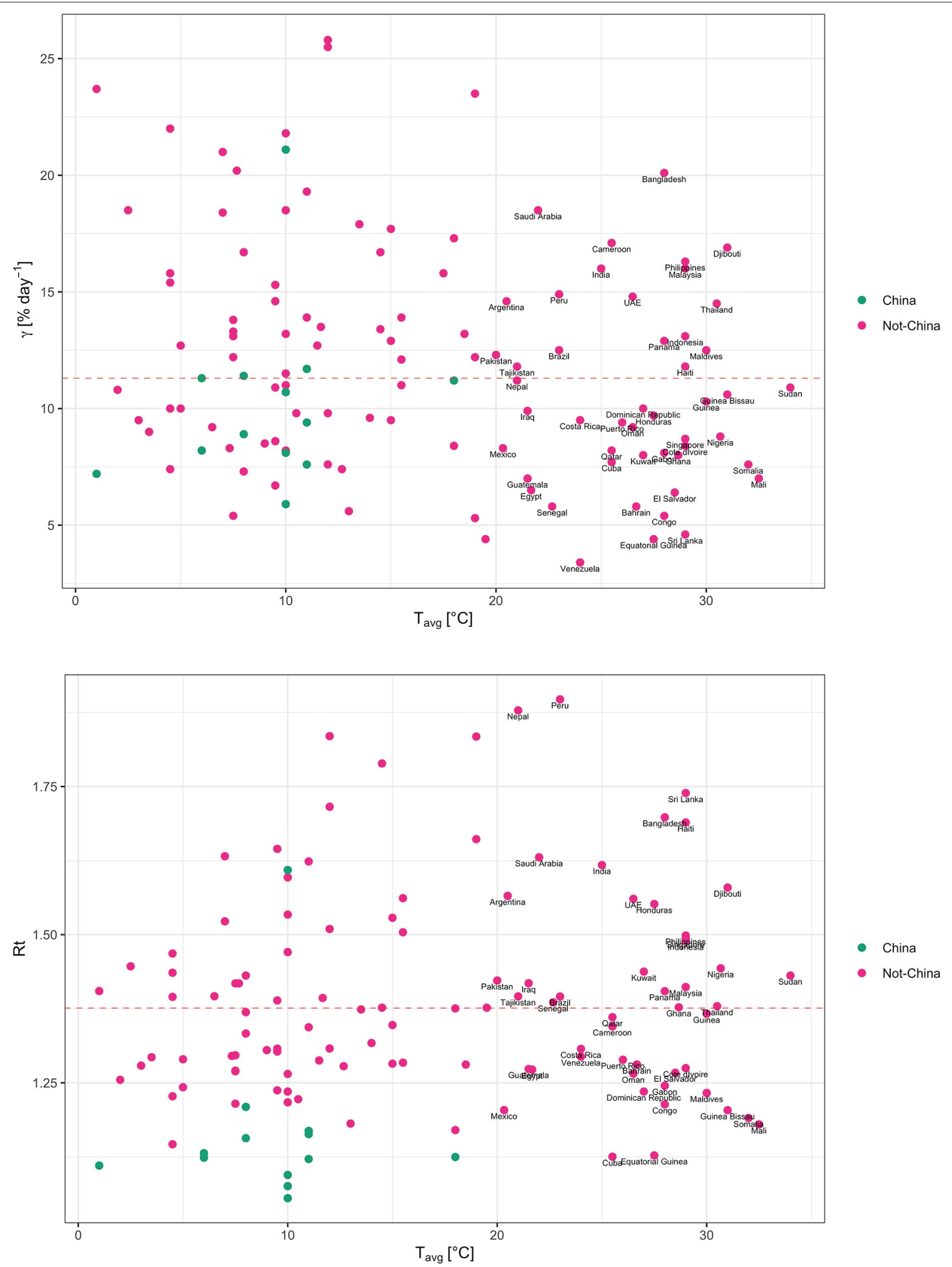

FIGURE 1 | The relationship between the apparent exponential rate of SARS-CoV-2 spread $(\gamma)$ and the Effective Reproductive number (Rt) and the average daily temperature $\left(T_{\text {avg }}\right)$ across nations and Chinese provinces for the period of exponential growth in number of cases of COVID-19 (data last accessed June 1, 2020, Figure S1). Green symbols represent provinces in China while red symbols represent other nations. 


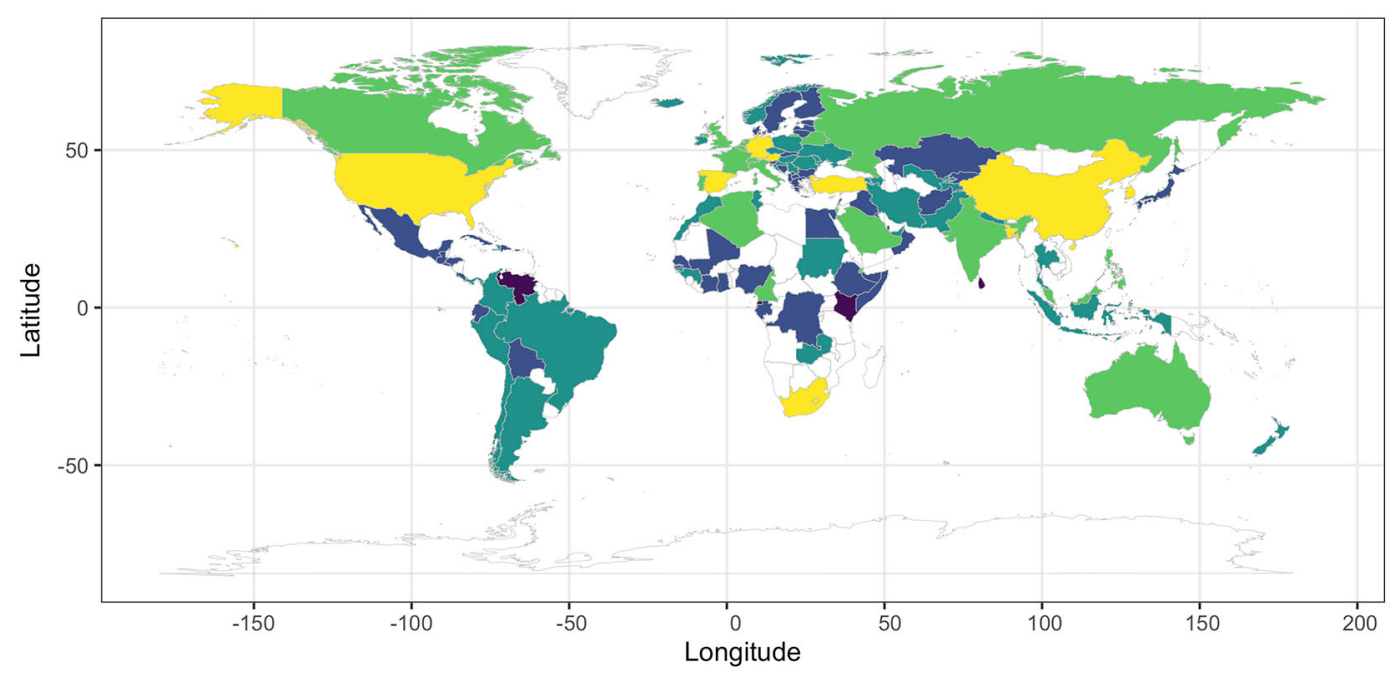

$\gamma\left[\%\right.$ day $\left.^{-1}\right]$

$00-05$

$05-10$

$10-15$

$15-20$

$20+$

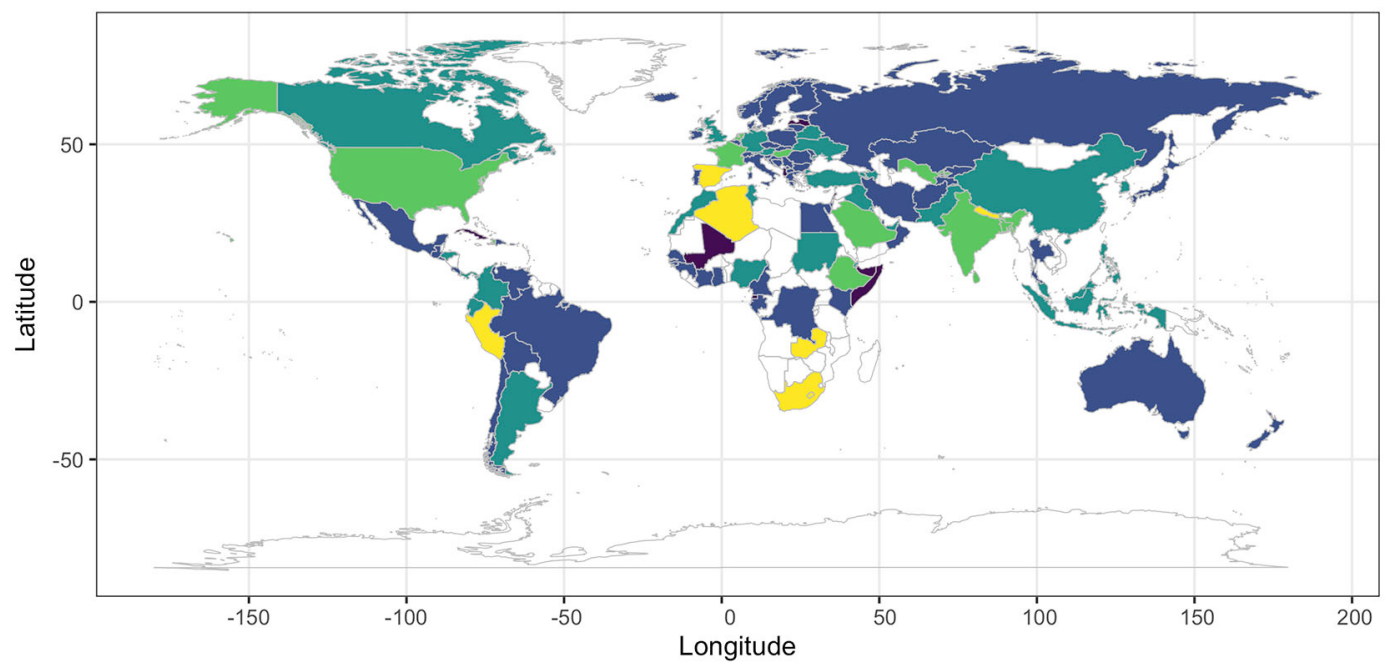

Rt

$1.0-1.2$

$1.2-1.4$

$1.4-1.6$

$1.6-1.8$

$1.8+$

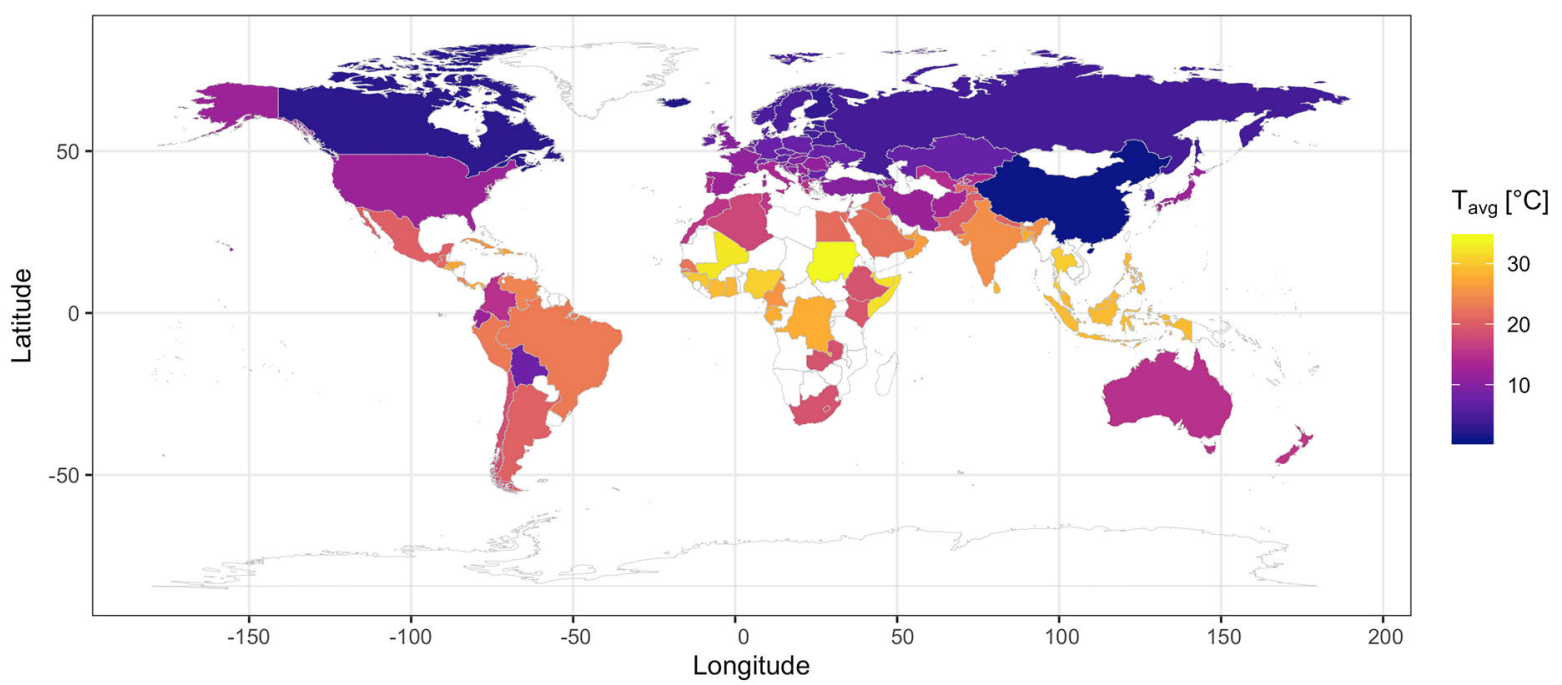

FIGURE 2 | Spatial distribution of the apparent exponential rate of SARS-CoV-2 spread $(\gamma)$ and the Effective Reproductive number (Rt) and the average daily temperature ( $T_{\text {avg }}$ ) across nations (data last accessed June 1, 2020). 
risk. Analysis based on studies in China reported contrasting relationship between spread rate and temperature, ranging from positive relationship reported for Wuhan, China (6), for Chinese cities with very low $\left(<3^{\circ} \mathrm{C}\right)$ ambient temperatures (7), or positive (8) or negative (9) relationships for provinces across China, and lack of relationship between spread rates and temperature across cities in China (10). We believe that the conflicting nature of these results may derived, as shown for our analysis at the global scale prior to May 15, from confounding factors, including the spread across provinces in China as well as confinement policies. In contrast to these analyses for China, based on the analysis of single time periods and including provinces and cities with very low number of cases, where calculations involve significant uncertainty, we repeated our analysis across time period spanning 3 months, as well as an analysis based on the initial exponential spread, before confinement measures flattened the spread rate. Indeed, our analysis, including provinces across China, unveiled the risk of such spurious relationships, such as that obtained using global data until 15 March, 2020, due to confounding factors associated with the routes of spread of the epidemic. Similar partial evidence for a decrease in spread rates with increasing temperature for Barcelona. Spain (11), is likely to have also confounded the relationship between temperature and spread rates with the effects of confinement policies that reduced spread rates in that city as temperature increased during the study period. Hence, our findings at the global scale, and consolidated across multiple time periods following the pandemic state, reject the hypothesis of a relationship between COVID-19 spread rates and ambient temperature, consistent with those of recent studies that also reported no evidence for an association of epidemic growth with temperature using different approaches and data (12).

Many countries have employed strong lockdown and mandated school closures and restrictions of mass gatherings, social distancing to slow the growth of COVID-19 pandemic, which have successfully contained the spread on most cases. Our results suggest that release plans from confinement should not assume that spread rates will decrease with warm summer temperatures.

Data sources: The data on COVID-19 is available publicly across many sources; where downloadable data files are updated daily few are listed below;

World health organization(https://www.who.int/emergencies/ diseases/novel-coronavirus-2019/situation-reports/).

Johns Hopkins CSSE (https://data.humdata.org/dataset/novelcoronavirus-2019-ncov-cases) [Accessed June 1, 2020].

European Centre for Disease Prevention and Control (https:// www.ecdc.europa.eu/en/publications-data/download-todays-

\section{REFERENCES}

1. Sajadi MM, Habibzadeh P, Vintzileos A, Shokouhi S, MirallesWilhelm F, Amoroso A. Temperature, Humidity, and Latitude Analysis to Estimate Potential Spread and Seasonality of Coronavirus data-geographic-distribution-covid-19-cases-worldwide) (accessed June 1, 2020).

\section{DATA AVAILABILITY STATEMENT}

Publicly available datasets were analyzed in this study. This data can be found here: World health organization (https:// www.who.int/emergencies/diseases/novel-coronavirus-2019/ situation-reports/); Johns Hopkins CSSE (https://data.humdata. org/dataset/novel-coronavirus-2019-ncov-cases) (accessed March 25, 2020); European Centre for Disease Prevention and Control (https://www.ecdc.europa.eu/en/publicationsdata/download-todays-data-geographic-distribution-covid-19cases-worldwide) (accessed March 26, 2020).

\section{AUTHOR CONTRIBUTIONS}

CD and TJ conceived, designed the research, and wrote the first draft. TJ conducted the analysis. All authors contributed to improving the paper and approved the submission.

\section{FUNDING}

This research was supported by funding provided by the King Abdullah University of Science and Technology to the CBRC.

\section{SUPPLEMENTARY MATERIAL}

The Supplementary Material for this article can be found online at: https://www.frontiersin.org/articles/10.3389/fpubh. 2020.00436/full\#supplementary-material

Figure S1 | The apparent average ( \pm SE) exponential rate of SARS-CoV-2 spread $(\gamma)$, the average (and 95\% confidence limits) of Effective Reproductive number of infection (Rt) and the average daily temperature $\left(T_{\text {avg }}\right)$ total case and number of days of the exponential growth period across nations and Chinese provinces where epidemics have been reported (data updated through May 31, 2020).

Figure $\mathbf{S 2}$ | The relationship between the apparent exponential rate of SARS-CoV-2 spread $(\gamma)$ and the Effective Reproductive number of infection (Rt) and the average daily temperature $\left(T_{\text {avg }}\right)$ across nations and Chinese provinces where > 100 cases of COVID-19 have been reported, as of Figure 1, but with data updated only until 15th March. The Gaussian function with temperature provided a significant fit for $\gamma$ with temperature.

Figure S3 | The relationship between the apparent exponential rate of SARS-CoV-2 spread $(\gamma)$ and the Effective Reproductive number of infection (Rt) and the average daily temperature ( $T_{\text {avg }}$ ) across nations and Chinese provinces where $>100$ cases of COVID-19 have been reported, as of Figure 1, but with all data updated only until 27th March.

Figure S4 | The relationship between the apparent exponential rate of SARS-CoV-2 spread $(\gamma)$ and the Effective Reproductive number of infection (Rt) and the average daily temperature $\left(T_{\text {avg }}\right)$ across nations and Chinese provinces, as of Figure 1, but with all data updated until 31st May. 
3. Tan J, Mu L, Huang J, Yu S, Chen B, Yin J. An initial investigation of the association between the SARS outbreak and weather: with the view of the environmental temperature and its variation. $J$ Epidemiol Commun Health. (2005) 59:186-92. doi: 10.1136/jech.2004. 020180

4. Gaunt ER, Hardie A, Claas EC, Simmonds P, Templeton KE. Epidemiology and clinical presentations of the four human coronaviruses 229E, HKU1, NL63, and OC43 detected over 3 years using a novel multiplex real-time PCR method. J Clin Microbiol. (2010) 48:2940-7. doi: 10.1128/JCM.00636-10

5. Jamil T, Duarte CM. Global Data Set on Spread of COVID-19 and Ambient Temperature [Data set]. Zenodo. (2020). doi: 10.5281/zenodo.3981482

6. Ma Y, Zhao Y, Liu J, He X, Wang B, Fu S, et al. Effects of temperature variation and humidity on the death of COVID-19 in Wuhan, China. Sci Total Environ. (2020) 724:138226. doi: 10.1016/j.scitotenv.2020. 138226

7. Zhu, Xie YJ. Association between ambient temperature and COVID-19 infection in 122 cities from China. Sci Total Environ. (2020) 724:138201. doi: 10.1016/J.SCITOTENV.2020.138201

8. Shi P, Dong Y, Yan H, Zhao C, Li X, Liu W, et al. Impact of temperature on the dynamics of the COVID-19 outbreak in China. Sci Total Environ. (2020) 728:138890. doi: 10.1016/j.scitotenv.2020.138890

9. Qi H, Xiao S, Shi R, Ward MP, Chen Y, Tu W, et al. COVID19 transmission in Mainland China is associated with temperature and humidity: a time-series analysis. Sci Total Environ. (2020) 728:138778. doi: 10.1016/j.scitotenv.2020.138778

10. Yao Y, Pan J, Liu Z, Meng X, Wang W, Kan H, et al. No association of COVID-19 transmission with temperature or UV radiation in Chinese cities. Eur Respir J. (2020) 55:2000517. doi: 10.1183/13993003.00517-2020

11. Tobías, Molina AT. Is temperature reducing the transmission of COVID-19? Environ Res. (2020) 186:109553. doi: 10.1016/j.envres.2020.109553

12. Jüni P, Rothenbühler M, Bobos P, Thorpe KE, Da Costa BR, Fisman DN, et al. Impact of climate and public health interventions on the COVID-19 pandemic: a prospective cohort study. Canad Med Assoc J. (2020) 192:E56673. doi: $10.1503 / \mathrm{cmaj} .200920$

Conflict of Interest: The authors declare that the research was conducted in the absence of any commercial or financial relationships that could be construed as a potential conflict of interest.

Copyright $\odot 2020$ Jamil, Alam, Gojobori and Duarte. This is an open-access article distributed under the terms of the Creative Commons Attribution License (CC BY).

The use, distribution or reproduction in other forums is permitted, provided the original author(s) and the copyright owner(s) are credited and that the original publication in this journal is cited, in accordance with accepted academic practice. No use, distribution or reproduction is permitted which does not comply with these terms. 